\title{
SELF EFFICACY DAN MOTIVASI TERHADAP HASIL BELAJAR MAHASISWA KEBIDANAN PADA MATA KULIAH ASUHAN PERSALINAN
}

\author{
Titi Purwitasari Handayani ${ }^{1}$ \\ 1Program Studi D3 Kebidanan STIKes Karsa Husada Garut \\ Email : titipurwitasarih30@gmail.com
}

\begin{abstract}
Background: Assessment of learning outcomes related to information about individual capabilities include cognitive, affective and psychomotor. Values obtained has a dual function, as the success of students studying subjects and tool evaluation of the success of the course. The factors that affect learning outcomes are internal and external factors. Self efficacy is a student self belief to face all the difficulties and obstacles during the lectures. Leraning motivation is closely related to urge students to take action to achieve desired goals. The tendency of self efficacy and learning motivation with improved student results to be internal factors that can affect the performance or effort on lectures.

Purpose: This study aim to analyze the correlation between self efficacy and motivation with the learning outcomes of Intranatal Care Diploma three Midwifery Garut district.

Method: This study used cross sectional design. Total Sampling used in samples of 203 student. This study was conducted in Diploma three Midwifery Garut on February 2017. The method of analysis using logistic regression.

Result : The results showed that self efficacy, instrinsic motivation, extrinsic motivation has no significant correlation to learning outcomes through logistic regression analysis. Self efficacy correlation to learning outcomes value of $p=0.819(p>0.05)$. Correlation intrinsic motivation and extrinsic motivation premises learning outcomes $p=0.699$ and $p=0.611$. Confounding variables that have significant with the high correlation school learning outcomes department value of $p=0.016(p<0.05)$ and the GPA $p=0.10(p<0.05)$.

Conclusion : Conclusion of the study were no significant correlation between self efficacy and motivation with the learning outcomes of Intranatal Care Students Diploma three Midwifery in Garut.

Suggestion: Educational institutions need to make a selection at the time of admission of new students by only accepting students with a high school background with a major in science. In the learning process it is better to pay attention to students who have a low GPA before the previous semester to be given specific guidance by academic supervisors so that they can study harder to produce good learning outcomes.
\end{abstract}

Keywords: self efficacy, motivation, learning outcomes.

\section{ABSTRAK}

Latar Belakang : Penilaian hasil belajar berkaitan dengan informasi mengenai kemampuan individu meliputi ranah kognitif, ranah afektif dan psikomotoris. Nilai yang diperoleh mempunyai fungsi ganda, sebagai keberhasilan peserta didik mempelajari mata kuliah dan alat evaluasi keberhasilan dari mata kuliah. Faktor yang memengaruhi hasil belajar yaitu faktor internal dan eksternal. self efficacy merupakan keyakinan diri mahasiswa untuk menghadapi segala kesulitan dan hambatan selama perkuliahan. Motivasi belajar berkaitan erat dengan dorongan mahasiswa untuk melakukan tindakan untuk mencapai tujuan yang diinginkan. Adanya kecenderungan self efficacy dan motivasi belajar dengan peningkatan hasil belajar mahasiswa sehingga menjadi faktor internal yang mampu memengaruhi kinerja atau usaha pada perkuliahan.

Tujuan : Untuk menganalisis hubungan self efficacy dan motivasi belajar dengan hasil belajar mata kuliah Asuhan Persalinan mahasiswa D3 Kebidanan di kabupaten Garut.

Metode : Penelitian ini menggunakan desain cross sectional. Pengambilan sampel dilakukan dengan cara total sampling dengan jumlah sebanyak 203 mahasiswa. Penelitian ini dilaksanakan di D3 Kebidanan Kabupaten Garut pada bulan Februari 2017. Metode analisis menggunakan uji regresi logistik.

Hasil : hasil menunjukkan self efficacy, motivasi belajar intrinsik, motivasi belajar ekstrinsik memiliki hubungan yang tidak signifikan dengan hasil belajar melalui analisis regresi logistik. Hubungan self efficacy dengan hasil belajar nilai $p=0,819(p>0,05)$. Hubungan motivasi belajar intrisik dan motivasi belajar ekstrinsik 
dengan hasil belajar nilai $p=0,699$ dan $p=0,611$. Variabel perancu yang memiliki hubungan yang signifikan dengan hasil belajar adalah Jurusan SMA nilai $p=0,016(p<0,05)$ dan IPK semester 2 nilai $p=0,10(p<0,05)$.

Simpulan : penelitian tidak terdapat hubungan signifikan antara self efficacy dan motivasi dengan hasil belajar mata kuliah Asuhan Persalinan mahasiswa D3 Kebidanan di Kabupaten Garut.

Saran Institusi pendidikan perlu melakukan seleksi saat penerimaan mahasiswa baru dengan hanya menerima mahasisea dengan latar belakang SMA dengan jurusan IPA. Dalam proses pembelajaran sebaiknya diperhatikan mahasiswa yang memiliki nilai IPK semester sebelumnya yang rendah agar diberikan bimbingan secara khusus oleh pembimbing akademik agar dapat belajar lebih giat untuk menghasilkan hasil belajar yang baik.

Kata Kunci : self efficacy, motivas, hasil belajar.

\section{PENDAHULUAN}

Pendidikan kebidanan di Indonesia dipengaruhi oleh kebutuhan tenaga bidan dalam upaya percepatan penurunan AKI (Angka Kematian Ibu) dan AKB (Angka Kematian Bayi) sehingga menyebabkan menjamurnya pendirian institusi pendidikan D3 Kebidanan yang berjumlah 679 institusi tahun 2011. Salah satu kunci utama peningkatan kesehatan melalui pendidikan yang berkualitas. Banyaknya jumlah institusi berkaitan erat dengan kualitas pendidikan yang diharapkan berdampak pada kompetensi lulusan perguruan tinggi tersebut, terutama peran ketika menjalankan profesi sebagai tenaga kesehatan di masyarakat. Faktor memengaruhi kualitas dari intitusi pendidikan yaitu input, proses, output dan outome. Salah satu faktor yang memengaruhi adalah faktor input dari institusi yaitu kurang baik kualitasnya, kualitas staf pengajar, metode mengajar, sistem evaluasi kurang memadai, dan kurangnya sarana penunjang. Berdasarkan hal tersebut diperlukan penilaian untuk meningkatkan dan mendukung kualitas pendidikan. (Kemenkes RI, 2011, Dirjen Dikti, 2010)

Beberapa penelitian yang menunjukkan mengenai kualitas dari lulusan instiusi pendidikan ketika menjalankan perannya di masyarakat, yaitu mengenai kualitas dari tenaga kesehatan di pelayanan kesehatan berdasarkan hasil penelitian dari Hufron dan Supratman mengenai analisis hubungan persepsi pasien tentang mutu pelayanan kesehatan dengan tingkat kepuasan pasien di Puskesmas Penumping Kota Surakarta. Hasil menunjukkan rata - rata bahwa pasien menilai mutu pelayanan rendah dengan kepuasan pasien $52,4 \%$ dari 22 responden.(Agus and Supratman, 2006)Hasil Penelitian Dwilaksono tentang strategi peningkatan kualitas jasa pelayanan berdasarkan analisis kepuasan ASKESKIN di Puskesmas Kota Surabaya, menunjukkan hasil yang tidak berbeda. Hasil penelitian menunjukkan dimensi kehandalan pelayanan kesehatan mendapatkan hasil presentase kepuasan yang paling rendah yaitu 82,4\%.(Agung, 2006) Penelitian yang dilakukan oleh Demsa Simbolon, Djazuli Chalidayanto dan Ernawati mengenai determinan kinerja pelayanan kesehatan ibu dan anak di Rumah Sakit pemerintah Indonesia (analisis data Rifaskes tahun 2011), bahwa sebagian besar pelayanan kesehatan ibu dan anak masih kurang optimal $(66,3 \%)$. Hasil penelitian berdasarkan kinerja pelayanan KIA yang diukur dari proses pelayanan yaitu koordinasi, evaluasi pelayanan dan ketanggapan pelayanan. (Simbolon et al., 2013)

Berdasarkan beberapa penelitian tersebut menunjukan kualitas pelayanan kesehatan yang dilakukan oleh tenaga kesehatan. Kualitas tenaga kesehatan berhubungan dengan kompetensi yang harus dimiliki oleh lulusan dari pendidikan kesehatan, karena seseorang dianggap berkompeten jika dianggap mampu oleh masyarakat dalam melaksanakan tugas - tugasnya. Hal ini sesuai dengan kompetensi yang diharapkan pendidikan DIII Kebidanan yang memiliki profil lulusan yaitu Care Provider, Communicator, dan Decision Maker. (Kemenkes RI, 2007, AIPKIND, 2011) Lulusan mahasiswa kebidanan mampu menjalankan tugas sebagai bidan pelaksana baik di institusi pelayanan maupun praktik perorangan. Kompetensi lulusan bidan meliputi pengetahuan, keterampilan dan sikap yang mampu menjamin pelayanan yang profesional dan akuntabilitas pada pelayanan kebidanan. (Kemenkkes RI, 2007)

Pendidikan DIII Kebidanan merupakan pendidikan vokasional yang menghasilkan Bidan pelaksana dengan gelar Ahli Madya Kebidanan. Berdasarkan kurikulum Diploma kebidanan tahun 2011, diselenggarakan pendidikan selama 6 semester dengan beban studi sebanyak 96 sks dengan pembelajaran teori sebanyak 40\% (39 SKS) dan pembelajaran praktek $60 \% \quad$ (57 $\quad$ SKS). Penyelenggaraan pembelajaran menggunakan metode pembelajaran Student Center Learning. $\mathrm{Hal}$ tersebut didukung oleh beberapa metode 
pembelajaran di kelas seperti diskusi, role play, demonstrasi, simulasi dan problem based learning. (Kemenkes RI, 2011)

Salah satu mata kuliah mahasiswa pada semeseter tiga yang berkaitan erat dengan profesi bidan adalah mata kuliah Asuhan Persalinan. Mata kuliah ini mampu menunjang kompetensi mahasiswa untuk menjalankan profesinya di masyarakat. Kompetensi yang diharapkan yaitu kemampuan untuk melaksanakan asuhan pada ibu bersalin normal dengan memperhatikan aspek budaya yang didasari konsep, sikap dan keterampilan seuai dengan evidence based dalam praktik intranatal menggunakan manajemen kebidanan yang berfokus pada upaya preventif dan promotif, deteksi dini dan pendokumentasian. Mata kuliah ini diselenggarakan dengan jumlah beban studi 5 SKS terdiri dari 2 teori dan 3 praktik. (Kemenkes RI, 2011)

Berdasarkan hasil studi pendahuluan, hasil belajar dari mata kuliah Asuhan Persalinan mahasiswa yang mengikuti remedial tahun akademik 2012/2013 ujian 54\% dari jumlah 128 mahasiswa sedangkan tahun akademik 2013/2014 ujian $62 \%$ dari jumlah 122 mahasiswa. Selain itu dilakukan studi pendahuluan melalui kuesioner dengan 30 pernyataan tentang persiapan mahasiswa pada kegiatan perkuliahan yang terdiri dari persiapan belajar, bantuan belajar, kemandirian belajar, mengikuti perkuliahan, kerjasama kelompok belajar disebar kepada 20 responden dari tingkat 1 dan tingkat 3. Hasil jawaban dari kuesioner yang diberikan kepada responden sebagian besar responden memberikan jawaban kadang - kadang. Berdasarkan hasil studi pendahuluan tersebut menggambarkan rendahnya semangat mahasiswa untuk memahami bahwa belajar merupakan suatu kebutuhan dengan demikian mahasiswa berusaha mendapatkan prestasi akademik yang baik selama kuliah di pendidikan.

Faktor - faktor yang memengruhi keberhasilan belajar individu yaitu faktor internal dan faktor eksternal. Faktor internal terdiri dari minat, kecerdasan, bakat dan motivasi. Faktor eksternal terdiri dari lingkungan belajar dan instrumen.(Poerwati, 2008, Djamarah and Zain, 2006) Faktor internal merupakan faktor yang secara langsung memengaruhi individu. Faktor internal individu yang memengaruhi kinerja akademik menurut Bandura dan Pintrinch yaitu self efficacy dan motivasi. Kinerja akademik adalah tindakan yang dilakukan oleh mahasiswa selama proses pembelajaran. Self efficacy mampu memprediksi langsung intensi dan perilaku. Hal ini berhubungan langsung dengan kontrol individu untuk melakukan perubahan perilaku. Keyakinan diri berupa usaha yang akan dilakukan untuk menghadapi tantangan atau kesulitan yang dihadapi.(Nilsen, 2009, Schwarzer)

Self efficacy merupakan bentuk keyakinan akan kemampuan melaksanakan tugas atau tindakan sehingga mencapai tujuan. Semakin tinggi self efficacy akan mengarahkan pada prestasi yang lebih baik dengan perilaku positif. Tingginya self efficacy akan memotivasi mahasiswa secara kognitif untuk bertindak lebih tekun terutama bila tujuan yang hendak dicapai sudah jelas. (Hamdu and Agustina, 2011a, Arikunto, 2012)

Pentingnya self efficacy yang dimiliki oleh peserta didik dalam mengikuti pembelajaran sesuai dengan penelitian yang telah dilakukan oleh Firouzeh mengenai self efficacy mampu memprediksi prestasi akademik mahasiswa, ditemukan bahwa terdapat hubungan antara efikasi diri dan prestasi akademik $(P=0,01)$. Self efficacy menjadi salah satu faktor yang dimiliki individu untuk membantu memprediksi prestasi akademik dan berperilaku.(Azar, 2013) Penelitian yang dilakukan oleh Dinda Novariandhini dan Melly Latifah bahwa self efficacy memiliki hubungan positif dengan motivasi intrinsik dan motivasi ekstrinsik sehingga memengaruhi prestasi akademik siswa. Self efficacy merupakan keyakinan terhadap diri sendiri, sehingga seseorang memiliki motivasi untuk mengerjakan dan menyelesaikan pekerjaan dengan baik.(Novariandhini and Melly, 2012)

Rendahnya motivasi belajar menjadi salah satu faktor yang berperan terhadap rendahnya kualitas lulusan sebuah perguruan tinggi. Berdasarkan penelitian Ghullam dan Lisa mengenai hubungan motivasi belajar terhadap prestasi belajar, dengan hasil penelitian besarnya koefisien korelasi ( $r$ ) yaitu sebesar 0,693 dengan taraf signifikan $1 \%$. Hal tersebut menunjukkan semakin tinggi motivasi belajar semakin baik prestasi yang diterima oleh seseorang. Pentingnya motivasi belajar mampu mendorong individu untuk melakukan aktivitas belajar sesuai dengan tujuan yang ingin dicapai.(Hamdu and Agustina, 2011b)

Motivasi berdasarkan theory of planned behavior merupakan intensi yang memengaruhi secara langsung perilaku individu. Berdasarkan teori Self Determination dibagi menjadi dua yaitu motivasi intrinsik dan ekstrinsik. Hal ini disesuaikan dengan teori Hamalik Uno, bahwa motivasi belajar terbagi menjadi dua terdiri dari motivasi instrinsik dan motivasi ekstrinsik. Motivasi instrinsik merupakan motivasi belajar yang berasal dari 
individu berupa keinginan berhasil, dorongan untuk memenuhi kebutuhan belajar serta harapan untuk mencapai cita - cita. Motivasi belajar ekstrinsik merupakan motivasi belajar yang berasal dari luar individu seperti penghargaan, lingkungan belajar yang kondusif dan kegiatan belajar yang menarik. (Glanz et al., 2008, Ryan and Deci, 2000, Hamalik, 2011, Uno, 2007)

Penilaian mengenai Efikasi diri dan Motivasi belajar menurut Shari membantu pendidik untuk memfasilitasi kemampuan keilmuan mahasiswa selama menjalani pendidikan di perguruan tinggi. Mahasiswa diharapkan ketika mengikuti proses pembelajaran akan mengarah pada perubahan tingkah laku. Perubahan perilaku akan diperoleh setelah siswa menyelesaikan proses pembelajarannya melalui interaksi dengan berbagai sumber belajar dan lingkungan belajar. Perubahan perilaku atau kemampuan baru siswa tersebut disebut hasil belajar. (Shari et al., 2006)

\section{METODE PENELITIAN}

Metode penelitian menggunakan metode kuantitatif, untuk Menganalisis hubungan antara self efficacy dan motivasi belajar dengan hasil belajar mata kuliah Asuhan Persalinan Mahasiswa DIII
Kebidanan di Kabupaten Garut. Variabel Bebas adalah self efficacy dan Motivasi, variabel terikat adalah hasil Belajar, Variabel Perancu adalah latar belakang jurusan sma, dan IPK semester II.

Populasi dalam penelitian ini adalah seluruh mahasiswa semester III. Sampel pada penelitian ini adalah Mahasiswa D3 Kebidanan semester III tahun akademik 2017/2018 pada periode penelitian yang memenuhi kriteria inklusi dan tidak termasuk kriteria eksklusi serta bersedia mengikuti penelitian dengan menandatangani lembar persetujuan responden. Teknik pengambilan sampel menggunakan total sampling yaitu Mahasiswa DIII kebidanan TK II semester III yaitu berjumlah 203 orang dari dua institusi kebidanan di Kabupaten Garut.(Sugiyono, 2009)

Jenis penelitian cross sectional yaitu untuk mengetahui hubungan antara variabel yang dilakukan pada saat bersamaan. Penelitian ini menggunakan data primer yang diperoleh secara langsung melalui pengisian kuesioner efikasi diri dan motivasi belajar kepada responden dan data sekunder yaitu berupa nilai mata kuliah Asuhan Persalinan, IPK, Latar Belakang Pendidikan dan Jurusan ketika SMA.

\section{HASIL DAN PEMBAHASAN}

Tabel 1 Distribusi Frekuensi variabel Efikasi Diri, Motivasi Belajar Intrinsik, Motivasi Belajar Ekstrinsik, Hasil Belajar, Latar Belakang Pendidikan, Jurusan, IPK Semester dua ( $\mathrm{N}=203$ )

\begin{tabular}{cllcc}
\hline \multicolumn{1}{c}{ Variabel } & \multicolumn{1}{c}{ Kategori } & $\mathrm{N}$ & $\%$ \\
\hline 1. & Efikasi Diri & Tinggi $(\geq$ median) & 114 & 56,2 \\
& & Rendah (<median) & 89 & 43,8 \\
2. & Motivasi Belajar Intrinsik & Tinggi $(\geq$ median) & 92 & 45,3 \\
& & Rendah (<median) & 111 & 54,7 \\
3. & Motivasi Belajar Ekstrinsik & Tinggi ( $\geq$ median) & 102 & 50,2 \\
& & Rendah (<median) & 101 & 49,8 \\
4. & Hasil Belajar & ( 2 median) & 107 & 52,7 \\
& & (<median) & 96 & 47,3 \\
5. Latar belakang SMA & Non SMA & 21 & 10,3 \\
& & SMA & 182 & 89,7 \\
6. Jurusan SMA & Non IPA & 38 & 18,7 \\
& & IPA & 165 & 81,3 \\
7. & IPK Semester II & Tinggi $(\geq 2,75)$ & 134 & 66 \\
\hline
\end{tabular}

Berdasarkan tabel 1 menunjukkan bahwa efikasi diri mahasiswa tinggi sebesar 114 responden $(56,2 \%)$. Motivasi belajar dibagi menjadi dua bagian yaitu motivasi belajar intrinsik dan motivasi belajar ekstrinsik. Motivasi belajar intrinsik sebagian besar rendah yaitu 111 responden $(54,7 \%)$ dan Motivasi belajar ekstrinsik tinggi 102 responden $(50,2 \%)$. Mahasiswa sebagian besar berasal dari latar belakang SMA sebanyak 182 $(89,7 \%)$, jurusan IPA sebanyak 165 orang $(81,3 \%)$, IPK semester II memiliki IPK tinggi adalah 102 mahasiswa dari 203 jumlah responden yaitu sekitar $50,2 \%$. 
Tabel 2 Hubungan Efikasi Diri, Motivasi Belajar Intrinsik, Motivasi Belajar Ekstrinsik, Latar Belakang Pendidikan, Jurusan SMA, dan IPK Semester 2 dengan Hasil Belajar

\begin{tabular}{|c|c|c|c|c|c|c|}
\hline \multirow{2}{*}{\multicolumn{2}{|c|}{ Variabel }} & \multirow[b]{2}{*}{ Kategori } & \multicolumn{2}{|c|}{ Hasil belajar } & \multirow[b]{2}{*}{ Total $n(\%)$} & \multirow[b]{2}{*}{$p$} \\
\hline & & & $\begin{array}{ll}\text { Tinggi } \\
\text { median) }\end{array}$ & $\begin{array}{l}\text { Rendah } \\
\text { (<median) }\end{array}$ & & \\
\hline 1. & Efikasi diri & $\begin{array}{l}\text { Tinggi } \\
\text { Rendah }\end{array}$ & $\begin{array}{l}62(30,5 \%) \\
45(22,2 \%)\end{array}$ & $\begin{array}{l}52(25,6 \%) \\
44(21,7 \%)\end{array}$ & $\begin{array}{l}114(56,2 \%) \\
89(43,8 \%)\end{array}$ & 0,568 \\
\hline & $\begin{array}{l}\text { Motivasi } \\
\text { Belaiar }\end{array}$ & Tinggi & $61(30 \%)$ & $50(24,6 \%)$ & $111(54,7 \%)$ & \multirow[t]{2}{*}{0,481} \\
\hline & Intrinsik & Rendah & $46(22,7 \%)$ & $46(22,7 \%)$ & & \\
\hline & Motivasi & Tinggi & $52(25,6 \%)$ & $50(24,6 \%)$ & $102(50,2 \%)$ & \multirow{2}{*}{0.682} \\
\hline & Ekstrinsik & Rendah & $55(27,1 \%)$ & $46(22,7 \%)$ & $101(49,8 \%)$ & \\
\hline & $\begin{array}{l}\text { Latar } \\
\text { belakang }\end{array}$ & Sma & $101(49,8 \%)$ & $81(39,9 \%)$ & $182(89,7 \%)$ & \multirow{2}{*}{0,019} \\
\hline & $\begin{array}{l}\text { pendidikan } \\
\text { sma }\end{array}$ & Non sma & $6(3,0 \%)$ & $15(7,4 \%)$ & $21(10,3 \%)$ & \\
\hline \multicolumn{2}{|c|}{ 5. Jurusan IPA } & $\begin{array}{l}\text { IPA } \\
\text { Non IPA }\end{array}$ & $\begin{array}{l}67(47,8 \%) \\
10(4,9 \%)\end{array}$ & $\begin{array}{l}66(77,1 \%) \\
30(14,8 \%)\end{array}$ & $\begin{array}{c}163(80,3 \%) \\
40(19,7 \%)\end{array}$ & $P<0,001$ \\
\hline & $\begin{array}{l}\text { IPK } \\
\text { Semester II }\end{array}$ & $\begin{array}{l}\text { Tinggi } \\
\text { Rendah }\end{array}$ & $\begin{array}{l}60(29,6 \%) \\
47(23,2 \%)\end{array}$ & $\begin{array}{l}74(36,5 \%) \\
22(10,8 \%)\end{array}$ & $\begin{array}{l}134(66 \%) \\
69(34 \%)\end{array}$ & 0,002 \\
\hline
\end{tabular}

Keterangan : berdasarkan uji chi square

Berdasarkan tabel 2 hasil analis yang dilakukan dengan menggunakan chi square pada masing - masing variabel bebas dan variabel perancu dengan masing-masing nilai: efikasi diri dengan nilai $p=0,568$, motivasi belajar intrinsik $p=$
0,481 , motivasi ekstrinsik $p=0,682$, latar belakang sma $p=0,019$, jurusan sma $p=0,000$ dan IPK semester dua $p=0,002$. Variabel yang mempunyai $p<0,05$ yaitu efikasi diri, latar belakang sma dan jurusan sma.

Tabel 3 Hasil Analisis Regresi Logistik

\begin{tabular}{lccccc}
\hline \multicolumn{1}{c}{ Variabel } & $\mathrm{B}$ & $\mathrm{SE}$ & $\operatorname{Exp}(\mathrm{B})$ & $\mathrm{P}$ & $95 \%$ C.I.for EXP(B) \\
\hline Efikasi Diri & 0,081 & 0,354 & 1,085 & 0,819 & $0,542-2,169$ \\
Motivasi Intrinsik & 0,126 & 0,325 & 1,134 & 0,699 & $0,599-2,146$ \\
Motivasi Ekstrinsik & $-0,176$ & 0,350 & 0,837 & 0,611 & $0,422-1,661$ \\
Latar Belakang & $-0,073$ & 0,766 & 0,930 & 0,924 & $0,207-4170$ \\
pendidika SMA & 1,445 & 0,598 & 4,241 & 0,016 & $1,313-13,697$ \\
Jurusan SMA & $-0,856$ & 0,331 & 0,425 & 0,010 & $0,222-0,831$ \\
IPK Semester 2 &
\end{tabular}

Keterangan : berdasarkan Uji Regresi Logistik

Hasil uji statistik dari tabel 3 di atas, diketahui bahwa variabel-variabel merupakan hasil akhir analisi multivariat regresi logistik, variabel yang memenuhi syarat dilakukan regresi linear, tetapi variabel tidak memenuhi syarat. Berdasarkan hasil analisis yang dilakukan dengan menggunakan regresi logistik menunjukan bahwa variabel perancu yang memiliki nilai $p<0,05$ adalah variabel jurusan sma nilai $p=0,016$ dan variable IPK semester 2 nilai $p=0,010$. Variabel independet memiliki nilai $p>0.05$, maka dapat disimpulkan bahwa hasil belajar memiliki hubungan tidak signifikan dengan efikasi diri dan motivasi belajar mahasiswa di mata kuliah Asuhan Persalinan.

\section{PEMBAHASAN}

Hasil penelitian dan analisis data menunjukkan bahwa seara statistik efikasi diri, motivasi belajar inrinsik dan motivasi belajar ekstrinsik mahasiswa tidak berhubungan dengan hasil belajar mata kuliah Asuhan Persalinan. Hasil analisis bivariat variabel bebas /independent efikasi diri, motivasi belajar intrinsik dan motivasi belajar ekstrinsik pada penelitian ini tidak berhubungan 
secara signifikan. Sedangkan variabel perancu seperti latar belakang SMA, jurusan SMA IPA, dan IPK semester dua berhubungan dengan hasil belajar mahasiswa pada mata kuliah Asuhan Persalinan. Berdasarkan hasil analisis multivariat dengan analisis logistik bahwa faktor yang hanya berhubungan dengan hasil belajar mahasiswa pada mata kuliah Asuhan Persalinan yaitu jurusan SMA dan IPK Semester dua.

Berdasarkan uji regresi logistik efikasi diri memiliki $p>0,05$ yaitu $p=0,819$ yang berarti menunjukkan bahwa efikasi diri mempunyai hubungan tidak signifikan dengan hasil belajar. Efikasi diri berdasarkan teori Planned Behavior menurut Ajzen (1991) menjelaskan bahwa perceived behavioral control sebagai analisis seseorang akan memutuskan untuk bertindak atau tidak menjalankan suatu perilaku. Perceived behavior control mengacu hal yang dirasakan akan memudahkan atau menghambat bila perilaku tersebut dilaksanakan, hal ini terkait dengan pengalaman - pengalaman masa lalu. Perceived behavior control berkaitan erat dengan teori Efikasi diri, yaitu keyakinan bahwa seseorang bisa menguasai situasi untuk mengatasi hambatan atau kesulitan sehingga tujuan tercapai dan mendapatkan hasil positif.(Wieber et al., 2009)

Mahasiswa yang memiliki efikasi yang memiliki efikasi diri yang tinggi akan menunjukkan antusiasme dan kepercayaan diri yang kuat. Oleh karena itu efikasi diri menentukan usaha yang dilakukan oleh mahasiswa untuk mengatasi persoalan maupun hambatan yang tidak diinginkan. Apabila seseorang sudah membentuk dan mengembangkan keyakinan bahwa dirinya mempunyai kemampuan yang baik dalam mencapai target, maka individu tersebut akan termotivasi untuk melakukan tugasnya dengan baik. Efikasi diri akan menjadi efektif bila didukung oleh kemampuan yang memadai dan keyakinan akan usaha serta hasil yang akan diperoleh.(Anita et al., 2007)

Berdasarkan hasil penelitian dari Nurhasnah bahwa tidak terdapat hubungan yang signifikan antara efikasi diri dengan indeks prestasi keberhasilan belajar hanya sebesar $0,7 \%$ dan berarti ada faktor lain (99,7\%) yang dapat memengaruhi indeks prestasi belajar. Tinggi rendahnya efikasi diri tidak memengaruhi prestasi yang diperoleh mahasiswa, hal ini berarti bahwa mahasiswa yang memiliki efikasi diri tinggi tidak menunjukkan antusiasme dan tidak menunjukkan diri yang kuat mengatasi kesulitan yang ditemui selama mengikuti pendidikan. (Nurhasnah, 2005)

Mata kuliah Asuhan persalinan berkaitan erat dengan perannya sebagai bidan ketika lulus kuliah D3 Kebidanan, hasil analisis data efikasi diri yang menunjukkan hubungan tidak signifikan berkaitan dengan hasil penelitian dari Anita mengenai efikasi diri dengan kematangan karir. Hasil dari penelitian tersebut memiliki pengaruh yang tidak signifikan. Hal ini dapat dijelaskan, untuk mencapai kematangan karir dibutuhkan pengetahuan mengenai diri sendiri, pengetahuan tentang pekerjaan, kemampuan merencanakan langkah - langkah karir serta usaha individu mengambil tindakan yang tepat.

Berdasarkan uji regresi logistik motivasi belajar instrinsik maupun motivasi belajar ekstrinsik memiliki $p>0,05$ yaitu $p=0,699$ dan $p=6,11$ yang berarti menunjukkan bahwa memiliki hubungan tidak signifikan dengan hasil belajar.

Ajzen (1991) berasumsi bahwa intensi merupakan faktor motivasional yang memengaruhi terjadi perilaku. Intensi sebagai niat seseorang untuk melakukan suatu tindakan. Semakin tinggi intensi seseorang maka akan memengaruhi hasil perilakunya. Tipe motivasi berhubungan dengan kegiatan yang dilakukan, atau alasan seseorang melakukan kegiatan tersebut, sehingga memengaruhi prestasi. Intensi sebagai suatu keputusan individu untuk bertindak atau memunculkan suatu perilaku.(Yoo et al., 2012, Gagne, 2009) Teori Self Determination dari Ryan dan Deci (2000) sangat berkaitan dengan teori motivasi, bahwa motivasi sangat penting pada proses pembelajaran. Mahasiswa yang termotivasi akan terdorong untuk melakukan sesuatu kegiatan. Tingkat motivasi setiap orang berbeda tergantung dari orientasi motivasi menyangkut sikap sesuai dengan tujuan yang dicapai.

Motivasi belajar merupakan kondisi psikologi yang mendorong seseorang untuk melakukan tindakan. Kuat lemahnya motivasi pada saat pembelajaran mempengaruhi keberhasilan dalam belajar. motivasi belajar menentukan intensitas usaha belajar bagi mahasiswa, sehingga motivasi menimbukan adanya aktifitas atau kegiatan. Motivasi belajar dibagi menjadi dua yaitu motivasi belajar intrinsik dan motivasi belajar ekstrinsik. Perbedaan yang paling mendasar adalah motivasi intrinsik mengacu pada melakukan sesuatu secara berkesinambungan karena menarik atau menyenangkan bagi diri sendiri dan motivasi ekstrinsik mengacu melakukan sesuatu karena mengarah ke hasil yang diinginkan seperti imbalan (reward) dan atau hukuman.(Ryan and Dec)

Berdasarkan hasil penelitian Putri mengenai pengaruh motivasi terhadap hasil belajar bahwa tidak ada pengaruh positif signifikan antara motivasi terhadap hasil belajar dengan nilai $p>0,05$. 
${ }^{52}$ Faktor lain yang memengaruhi hasil belajar yaitu faktor lingkungan yang merupakan tempat peserta didik dan lingkungan tempat tinggal serta lingkungan sosial budaya. Faktor instrumental merupakan seperangkat kelengkapan yang terdapat pada institusi pendidikan terdiri dari kurikulum, prigram pengajaran, sara prasanan dan tim pengajar.

Faktor yang dipertimbangkan dalam penelitian ini untuk mengetahui faktor yang berhubungan dengan hasil belajar yaitu latar belakang pendidikan, jurusan saat SMA/Sederajat, IPK semester 2.

Latar belakang SMA tidak memiliki hubungan yang signifikan terhadap hasil belajar berdasarkan pengolahan data analisis uji regresi logistik yaitu $p>0,05$ yaitu $p=0,982$. Pada penelitian ini asal jurusan saat SMA mahasiswa berhubungan dengan hasil belajar mahasiswa pada mata kuliah Asuhan Persalinan nilai $p<0,05$ yaitu $p=0,16$. Mahasiswa yang memiliki hasil belajar tinggi sebagian besar berasal dari jurusan IPA. Mahasiswa kebidanan sebaiknya berasal dari SMA dengan jurusan IPA atau sekolah kejuruan kesehatan yang dapat menunjang terhadap proses pembelajaran. Hal ini disebabkan dapat mempermudah mahasiswa mendapatkan pembelajaran yang berhubungan dengan peran profesinya sebagai bidan terutama pada mata kuliah Asuhan Persalinan.

Mahasiswa yang berasal dari jurusan non kesehatan masih banyak sehingga mahasiswa mendapatkan nilai mata kuliah Asuhan Persalinan dengan nilai rendah. Seharusnya hasil belajar asuhan persalinan memiliki nilai yang tinggi, karena merupakan kompetensi inti dalam pendidikan kebidanan. Pendidikan kebidanan merupakan salah satu disiplin ilmu yang menitik beratkan pada pemikiran logis sehingga sebagai modal dasar pendidikan maka sebaiknya jurusan pada saat SMA adalah jurusan IPA atau kesehatan, sebab pada saat SMA mata pelajaran yang didapatkan berkaitan dengan pelajaran saat perkuliahan berlangsung sehingga mahasiswa dapat beradaptasi dengan baik. Mata kuliah program studi kebidanan lebih mudah dijalani oleh mahasiswa yang mempunyai dasar pelajaran Biologi, Kimia, Fisika, Matematika saat SMA, seperti mata kuliah dasar ditingkat 1.

Mahasiswa yang bukan berasal dari jurusan IPA atau kesehatan akan kesulitan menerima pembelajaran. Seperti yang diungkapkan oleh Wulansari bahwa prestasi mahasiswa dari jurusan IPA/Kesehatan lebih tinggi dibanding dengan anak dari jurusan IPS atau non Kesehatan.
Selain asal jurusan saat SMA yang menjadi modal dasar pembelajaran semester selanjutnya adalah nilai yang didapatkan pada setiap akhir semester yaitu Indeks Prestasi Kumulatif (IPK). Pada penelitian ini mahasiswa yang memiliki hasil belajar tinggi Asuhan Persalinan sebagian besar memiliki IPK semester dua yang tinggi dibandingkan dengan mahasiswa yang memiliki hasil belajar yang rendah. Pada pendidikan kebidanan sesuai dengan kurikulum inti bahwa pembelajaran di semester sebelumnya merupakan prasyarat untuk melanjutkan pada semester selanjutnya IPK pada semester dua sebagai dasar penguasaan teori keterampilan dasar.

Faktor lain yang memengaruhi hasil belajar yaitu faktor lingkungan yang merupakan tempat peserta didik dan lingkungan tempat tinggal serta lingkungan sosial budaya. Faktor instrumental merupakan seperangkat kelengkapan yang terdapat pada institusi pendidikan terdiri dari kurikulum, program pengajaran, sarana prasana dan tim pengajar.

\section{SIMPULAN}

Berdasarkan pengujian hasil penelitian mengenai hubungan efikasi diri dan motivasi belajar dengan hasil belajar mahasiswa DIII Kebidanan di Kabupaten Garut dapat ditarik simpulan bahwa tidak terdapat hubungan signifikan antara efikasi diri dan motivasi belajar dengan hasil belajar mahasiswa pada mata kuliah Asuhan Persalinan.

\section{SARAN}

Penelitian memiliki saran untuk penelitian selajutnya terutama mengenai hasil belajar mahasiswa dengan meneliti variabel lain seperti faktor lingkungan belajar maupun faktor instrumen (sarana prasarana, kurikulum maupun metode pembelajaran). Institusi pendidikan perlu melakukan seleksi saat penerimaan mahasiswa baru dengan hanya menerima mahasisea dengan latar belakang SMA dengan jurusan IPA. Dalam proses pembelajaran sebaiknya diperhatikan mahasiswa yang memiliki nilai IPK semester sebelumnya yang rendah agar diberikan bimbingan secara khusus oleh pembimbing akademik agar dapat belajar lebih giat untuk menghasilkan hasil belajar yang baik.

\section{DAFTAR PUSTAKA}

AIPKIND. Pendidikan Bidan Indonesia .

Agung, D. 2006. Strategi Peningkatan Kualitas Jasa Pelayanan Berdasarkan Analisis Kepuasan Pasien ASKESKIN di Puskesmas ( Studi Kasus di Puskesmas Mulyorejo dan Bayu 
Urip, Kota Surabaya). Buletin Penelitian

Sistem kesehatan, 9.

Agus, H dan Supratman.2006. Analisis Hubungan Persepsi Pasien Tentang Mutu Pelayanan Kesehatan dengan Tingkat Kepuasan Pasien di Puskesmas Penumping Kota Surakarta. Berita IImu Keperawatan, 1.

Anita, Taganing, Retnaningsih, Hamdi dan Tjut.2007. Pengaruh Locus Of Control dan Efikasi Diri Terhadap Kematangan Karis Siswa Sekolah Menengah Atas (SMA). Proceeding PESAT (Psikologi, Ekonomi, Sastra, Arsitek dan Sipil), 2.

Arikunto, S. 2012. Dasar - dasar Evaluasi Pendidikan. Jakarta. Bumi Aksara.

Azar, F. S. 2013. Self Efficacy, Achievement Motivation and Academic Proscanitation As Predictor of Academis Achievement in Pre College Students. Proceeding of The Global Summit on Education.

Dewi, M dan Aminah, M. 2016. Pengaruh Edukasi Gizi terhadap Feeding Practice Ibu Balita Stunting Usia 6-24 Bulan. Indonesian Journal of Human Nutrition, 3.

Djamarah, S. B. \& Zai, A. 2006. Strategi Belajar Mengajar. Bandung. PT Rineka Cipta.

Gagne, M. 2009. A Model Of Knowledge Sharing Motivation. Wiley Periodical Human Resource Management, 48.

Glanz, K., Rimer, B. K. dan Viswanath, K. 2008. Health Behavior and Health Education Theory, Research and Practice. In: ORLEANS, T. (ed.). San Francisco: Jossey Based a Wiley Imprint.

Hamalik, O. 2011. Proses Belajar mengajar. Jakarta, PT. Bumi Aksara.

Hamdu, G. \& Agustina, L. 2011b. Pengaruh Motivasi Belajar Siswa Terhadap Prestasi Belajar IPA di Sekolah Dasar (Studi Kasus terhadap Siswa Kelas IV SDN Tarumanagara Kecamatan Tawang Kota Tasikmalaya). Jurnal Penelitian Pendidikan, 12.

Ho, L.A. 2009. The Antecedents Of E-Learning Outcome An Examination Of System Quality Technology, Readliness and Learning BehaviourProquest Sociology.

Kartika, L. dan Mastuti, E. Motivasi Membaca Literatur Berbahasa Inggris pada Mahasiswa Psikologi Universitas Airlangga Surabaya.
Kemenkes RI. 2011. Kurikulum Inti Pendidikan Kebidanan. Kementrian Kesehatan RI.

Kursukar, R. A., Croiset, G., Garre, F. G. dan Cate, O. T. 2013. Motivational profiles of medical students: Association with study effort, academic performance and exhaustion. BMC Medical Education.

Nilsen, H. 2009. Influence on Student Academic Behaviour through Motivation, Self-Efficacy and Value Expectation: An Action Research Project to Improve Learning. Issues in Informing Science and Information Technology, 6.

Novariandhini, D.A dan Melly, L. 2012. Harga diri, efikasi diri, Motivasi Belajar dan Prestasi Akademik Siswa SMA pada berbagai model pembelajaran. Jurnal IImu Keluarga dan Konseling, 5.

Nobelina, A dan ALfi, P. 2011. Efikasi Diri, Dukungan Sosial Keluarga dan Self Regulated Learning pada Siswa Kelas VIII. Humanitas, VIII.

Nurhasanah. 2005. Hubungan Efikasi Diri dan Indeks Prestasi Keberhasilan Belajar. Lembaran Publikasi IImiah Pusdiklat Migas, 13.

Poerwati, T. 2008. Pengaruh Perilaku Belajar dan Motivasi Terhadap Prestasi Akademik Mahasiswa Akuntansi di Universitas STIKUBANK (UNISBANK) Semarang. Jurnal UNPAND.

Ryan, R. M. dan Deci, E. L. 2000. Intrinsic and Extrinsic Motivations: Classic Definitions and New Directions. Contemporary Educational Psychology, 25.

Schwarzer, R. Self Efficacy and Health Behavior Theories.

Shari, Britner dan Pajares, F. 2006. Sources of Science Self-Efficacy Beliefs of Middle School Students. Journal of Research in Science Teaching.

Shihusa, $\mathrm{H}$ dan Keraro, F.N. Using Advance Organizers to Enhance Students' Motivation in Learning Biology.

Simbolon, D, Chalidyanto, D dan Ernawati. 2013. Determinan Kinerja Pelayanan Kesehatan Ibu dan Anak di Rumah Sakit Pemerintah Indonesia (Analisis Data Rifaskes 2011). Jurnal Kebijakan Kesehatan Indonesia, 02.

Syah, M. 2013. Psikologi Pendidikan. 
Sugiyono. 2009. Statistika untuk Penelitian, Bandung, Penerbit Alfabeta.

Uno, H. 2007. Teori Motivasi dan Pengukurannya, Jakarta, PT. Bumi Aksara.

Wieber, F, Odenthak, G dan Gollwitzer, P.. 2009. Self Efficacy Feeling Moderate
Implementation Intention Effects. Psychology Press, 9.

Yoo, S. J., Han, S. H. dan Huang, W. 2012. The roles of intrinsic motivators and extrinsic motivators in promoting e-learning in the workplace: A case from South Korea Sun Joo. Elsevier Computer Human Behavior. 